\title{
Políticas de esporte, lei orgânica e financiamento nos municípios catarinenses
}

\section{Sport policies, organic law and financing in Santa Catarina municipalities}

\section{Políticas deportivas, ley orgánica y financiamiento en los municipios de Santa Catarina}

iD) Edmilson Santos dos Santos

Universidade Federal do Vale do São Francisco, Petrolina, Pernambuco, Brasil.

E-mail: edmilsonss.univasf@gmail.com

Resumo: O presente ensaio busca analisar o papel das instituições (poderes executivo e legislativo) na garantia do que está previsto no artigo 217 da CF/88: o esporte como direito de todos. Para tanto, o trabalho busca explorar o encaixe entre regras da federação e a expectativa da garantia do direito, tendo como cenário o estado de Santa Catarina. Serão analisadas duas instâncias federativas, a União e o município. O primeiro aspecto importante é que nem a União nem os municípios estão obrigados a implementar políticas de esporte. Há um vácuo institucional e a instituição responsável por preenchê-lo é o poder legislativo, como prevê o artigo 24 da CF/88. A inexistência de competências endereçadas ao poder executivo, contudo, não tem impedido a produção de políticas públicas de esporte.

Palavras-chave: Federalismo. Políticas Públicas. Esporte.

Abstract: This essay seeks to analyze the role of institutions (executive and legislative powers) in ensuring what is provided by article 217 of the Federal Constitution of 1988: sport as a right for all. Therefore, the 
study aims to explore the fit between the rules of the federation and the expectation of the guarantee of right, having as a scenario the state of Santa Catarina. Two federative instances will be analyzed, Union and municipality. The first important aspect is that neither the Union nor the municipalities are obliged to implement sports policies. There is an institutional gap and the institution responsible for filling it is the legislative power, as stated in article 24 of FC/88. The lack of competences addressed to the executive power has not prevented the production of public sports policies.

Keywords: Federalism. Public Policies. Sport.

Resumen: Este ensayo busca analizar el papel de las instituciones (poderes ejecutivo y legislativo) para garantizar lo previsto en el artículo 217 del CF / 88: el deporte como un derecho de todos. Con este fin, el trabajo busca explorar el ajuste entre las reglas de la federación y la expectativa de garantía del derecho, en el contexto del estado de Santa Catarina. Se analizarán dos instancias federativas, la Unión y el municipio. El primer aspecto importante es que ni la Unión ni los municipios están obligados a implementar políticas deportivas. Existe un vacío institucional y la institución responsable de llenarlo es el poder legislativo, como se establece en el artículo 24 del CF / 88. La falta de competencias dirigidas al poder ejecutivo no ha impedido la producción de políticas deportivas públicas.

Palabras clave: Federalismo. Políticas públicas. Deporte.

Submetido em: 05-12-2019

Aceito em: 25-05-2020 
Políticas de esporte, lei orgânica e financiamento nos municípios catarinenses

\section{Introdução}

As teorias neoinstitucionalistas aplicadas às análises das políticas públicas buscam, em linhas gerais, compreender o papel das instituições no resultado da política. Avaliam se os interesses de um ator central serão ou não suficientes para modelar seu resultado. As instituições podem ser de dois tipos: as formais, aquelas produzidas pelas normas e procedimentos para regular o comportamento dos atores; e as informais, aquelas que representam os constrangimentos causados pelos regramentos sociais ou culturais (THÉRET, 2003; HALL; TAYLOR, 2003; MARCH; OLSEN, 2008).

Tanto as instituições formais como as informais podem afetar a distribuição dos recursos na sociedade. Minimizam as incertezas, ajudam a compreender os limites à maximização das preferências dos atores e interferem no cálculo estratégico à tomada de decisão sobre as políticas, inclusive as de esporte e de lazer (MENDES, 2013; WERLE; VAZ, 2019).

$\mathrm{Na}$ área das políticas públicas de esporte no Brasil, a análise das instituições tem sido pouco explorada, apesar da confiança incondicional ao que propõe a Constituição Federal de 1988 (CF/88), no seu artigo 217: o fomento ao esporte é um dever do Estado (BRASIL, 1988). O Estado brasileiro, como estrutura de funcionamento das instituições de governo, como o poder executivo e o poder legislativo, tem no modelo federalista uma instituição que pode ajudar a compreender o comportamento dos atores e o resultado líquido das políticas públicas (ARRETCHE, 2010; ABRUCIO; FRANZESE, 2007).

Após promulgação da carta constitucional, todos os municípios brasileiros, elevados a entes da federação, tiveram que elaborar suas leis orgânicas - a constituição municipal. Na medida em que a CF/88 não impôs veto à participação dos municípios na oferta de políticas públicas de esporte e nem Ihes impôs responsabilidade, coube aos legisladores municipais produzirem um entendimento local sobre o tema. Considerando que o município é apenas parte 
Políticas de esporte, lei orgânica e financiamento nos municípios catarinenses Edmilson Santos dos Santos

do Estado e não responde por ele de forma solitária, a não inclusão do tema em sua lei orgânica não traria, em tese, impedimentos à sua efetivação por parte dos outros entes federados.

A engenharia federalista ${ }^{1}$ premiou o município com autonomia para incluir ou não o tema do esporte em sua lei orgânica. A inclusão poderia ser realizada na seção que trata das competências do município, que delimita com precisão suas responsabilidades, ou naquela que trata especificamente do esporte. Nesse sentido, os constrangimentos produzidos na norma poderiam ampliar ou restringir o comportamento dos decisores nessa matéria, com impacto na agenda de investimentos dos municípios.

Diante desse cenário, elaboramos a seguinte pergunta de pesquisa: O comportamento alocativo (financeiro) dos municípios em matéria esportiva pode ser explicado pelos imperativos produzidos pela Lei Orgânica Municipal?

A escassez do debate em torno das relações entre esses dois aspectos da implementação das políticas de esporte, a lei orgânica e a capacidade de investimento são exploradas aqui a partir do estado de Santa Catarina. Três são as motivações para a escolha do estado: (a) as dificuldades operacionais de realizar uma investigação que reúna aspectos financeiros e interpretativos das leis orgânicas dos 5.570 municípios nos levam à escolha de apenas uma Unidade da Federação; (b) a necessidade de utilizar dados comparativos de gastos em políticas de esporte por parte dos municípios e de analisar as leis orgânicas exige a escolha de um estado com menor número de municípios, como Santa Catarina, o menor da região Sul; (c) o estado pertence a uma das regiões de maior desenvolvimento econômico e social do Brasil, portanto, apresenta elementos comparativos diferenciados em termos de recursos à agenda esportiva.

Assim, o presente trabalho tem como objetivo analisar o comportamento alocativo dos municípios do estado de Santa Catarina frente aos regramentos produzidos pelas leis orgânicas em maté-

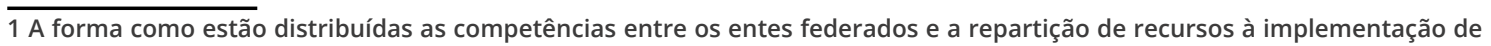
uma dada agenda política. 
Políticas de esporte, lei orgânica e financiamento nos municípios catarinenses Edmilson Santos dos Santos

ria esportiva. Como objetivos específicos: (a) analisar a agenda esportiva dentro das competências municipais e na seção que trata do esporte nas leis orgânicas municipais; (b) analisar a adesão ao investimento em políticas públicas de esporte e sua evolução ao longo das gestões.

\section{As normas e o financiamento das políticas de esporte}

São raros os trabalhos que analisam o comportamento alocativo dos municípios brasileiros a partir da análise de suas leis orgânicas. No entanto, recentemente, têm surgido trabalhos que tematizam as leis orgânicas no escopo da análise das políticas públicas municipais.

Souza et al. (2017), ao analisarem as políticas públicas na cidade de Barra do Rocha/BA, identificaram que a norma local está em consonância com o que preconiza a CF/88. Ávila, Bahia e Rosa (2019) analisaram a ocorrência de leis orgânicas em 59 municípios de 4 Territórios de Identidade do estado da Bahia.

A análise mais sofisticada veio de Santos, Freire e Bastos (2017), que analisaram 13 leis orgânicas de municípios do estado de São Paulo a partir de 6 eixos temáticos: esporte formal e informal; esporte e educação física; conselho municipal de esporte; orçamento para o esporte; esporte para pessoas com deficiência; instalações esportivas. O estudo constatou que há baixo grau de exercício da autonomia auferida pela CF/88. Ou seja, a legislação é deficitária para tratar do tema da política pública esportiva, apesar da liberdade para ampliar o acesso à política.

Uma das lacunas importante desses trabalhos diz respeito ao debate sobre a competência dos municípios na implementação das políticas esportivas, e outra, a eficácia da norma. Ao garantir que as leis orgânicas pudessem se debruçar sobre os temas de interesse local, principalmente a partir do direito ao esporte, inscritos nos artigos 30, Inciso I, e 217 da CF/88, havia uma expectativa de que houvesse maior protagonismo dos municípios na oferta de 
Políticas de esporte, lei orgânica e financiamento nos municípios catarinenses Edmilson Santos dos Santos

políticas públicas de esporte como competência dessa esfera de governo.

A eficácia da norma diz respeito à sua aplicabilidade, pode ser plena, contida ou limitada, como destacam Silva (2012) e Lenza (2008). As normas de eficácia plena apresentam aplicabilidade imediata. Não é necessária sua regulamentação e os efeitos são imediatos à promulgação da lei orgânica. As normas de eficácia contida exigem aplicabilidade imediata, mas admitem que o legislador possa restringir o seu alcance. As normas de eficácia limitada precisam do legislador para produzir eficácia máxima.

A previsão de gasto nas políticas públicas é um bom preditor do comportamento dos governos no âmbito da política, como revela Ribeiro (2006). As análises sobre o comportamento financeiro dos municípios têm permitido observar a participação desse nível de governo na oferta de políticas públicas de esporte. Os trabalhos produzidos nos últimos anos têm demonstrado o papel importante dos municípios no financiamento das políticas públicas de esporte e de lazer (SANTOS et al., 2019; SANTOS et al., 2019; SANTOS; MENEZES; LIMA, 2019; SANTOS; CARVALHO; FROES, 2019; SANTOS; CANAN; STAREPRAVO, 2018; SANTOS; SANTOS, 2018; SANTOS; STAREPRAVO; CANAN, 2018; SANTOS, 2018; SANTOS; STAREPRAVO, 2018; SANTOS; HIRATA, 2017; GRASSO; ISAYAMA, 2017).

Esses dois elementos, a norma e o investimento, quando analisados de forma cruzada, permitem avaliar o peso da primeira na definição do comportamento do segundo. Dessa maneira, é possível observar em que medida as normas são preditoras do tipo de comportamento que os municípios terão em termos de alocação financeira para as políticas públicas de esporte. No caso específico aqui em pauta, a preocupação se restringe ao esporte. Dessa forma, desconsidera o binômio esporte e lazer, que caracteriza a maior parte dos estudos na área, que incorporam o lazer como pertencente ao campo de análise. Considerando que as fontes do lazer também podem vir de outras áreas, como a cultura, extraímos esse componente da nossa análise. 
Políticas de esporte, lei orgânica e financiamento nos municípios catarinenses

\section{Metodologia}

O estado de Santa Catarina possui 295 municípios e está localizado na região Sul do Brasil. A escolha aleatória de um conjunto de leis orgânicas permitiu ter uma amostra do lugar da agenda esportiva na principal norma municipal. Como nem todas as prefeituras disponibilizam pela Internet essas leis, realizamos a captura aleatória de, no mínimo, 30\% das leis orgânicas disponibilizadas on-line, no período de 12 de outubro a 7 de novembro de 2019. Os municípios que não apresentavam suas leis orgânicas na web foram descartados e substituídos por outros, escolhidos também de forma aleatória. Ao final, a amostra foi composta por 30,17\% (89) das leis orgânicas do estado.

Dois aspectos foram observados nas leis orgânicas: a seção que trata das competências municipais e a que trata do esporte. Nas duas seções, buscou-se identificar aquelas normas de eficácia plena que imputam algum nível de obrigatoriedade de implementação de políticas de esporte (as normas de eficácia plena e contida, para efeito desse estudo, serão tratadas aqui como normas de 'eficácia garantida'; e as de eficácia limitada, como 'não garantida'). Para tanto, observou-se quatro dimensões da norma: (1) as competências municipais; (2) aquelas associadas ao financiamento, (3) aos equipamentos, (4) aos programas. Os quatro aspectos podem apresentar constrangimentos que impactam o financiamento do esporte quando exigem a ação do governo.

As políticas de esportes podem ser monitoradas através da unidade de gasto do setor público brasileiro, chamada de Função Desporto e Lazer (FDL). Ela foi regulamentada através da Portaria n. ${ }^{\circ} 42$, de 14 de abril de 1999, do Ministério do Planejamento, Orçamento e Gestão, e permite acompanhar as preferências dos governos no que diz respeito à função (BRASIL, 1999). Essa unidade de gasto possui quatro subfunções: Desporto Rendimento (DR); Desporto Comunitário (DC), Lazer (L) e Demais subfunções do Esporte e do Lazer (DsEL). Considerando que a análise aqui 
Políticas de esporte, lei orgânica e financiamento nos municípios catarinenses Edmilson Santos dos Santos

realizada contempla apenas as políticas de esporte, subtraímos os gastos na subfunção Lazer, e entendemos como compondo as políticas esportivas aquelas realizadas no DR, DC e DsEL.

A análise da adesão dos municípios à agenda de investimentos em políticas públicas de esporte contempla quatro cenários: (1) 295 municípios, população; (2) amostra, 89 municípios; (3) subamostra ' $a$ ', municípios que não apresentaram normas de eficácia plena dentro da amostra, 56 municípios; (4) subamostra 'b', municípios que apresentaram normas de eficácia plena dentro da amostra, 33 municípios.

Quanto ao financiamento, duas questões foram observadas: (1) a adesão à agenda de gasto em políticas de esporte e (2) a variação do gasto. A adesão busca observar o investimento ano a ano e foi aferida de forma a identificar o percentual de tempo em que houve investimento no esporte. A variação do financiamento avaliou o quanto o investimento variou de uma gestão para outra. Considerando que o registro do gasto por subfunção inicia-se em 2005, analisaremos apenas 3 gestões: Gestão 1 (G1), 2005/2008; Gestão 2 (G2), 2009/2012; e Gestão 3 (G3), 2013/2016. A variação (V) do gasto será realizada observando dois momentos: V1, G1 para G2; e V2, G2 para G3. Para esse nível da análise, os dados financeiros foram agregados por gestão. Utilizamos como deflator o Índice de Preço ao Consumidor (IPC) para o período.

\section{Análise dos resultados}

O artigo 217 da CF/88 considera que é dever do Estado fomentar a prática esportiva. O Estado deve ser interpretado como um conjunto de instituições que garante materialidade de suas ações: o poder executivo, o poder legislativo, o poder judiciário e os entes federados.

O fomento não explicita o tipo de comportamento que o poder executivo deve ter em relação às manifestações esportivas, a saber: esporte educacional, esporte rendimento e esporte partici- 
Políticas de esporte, lei orgânica e financiamento nos municípios catarinenses Edmilson Santos dos Santos

pação. No entanto, a estrutura de competências inscritas na constituição indicou o esporte como pertencente a um ou mais entes federados e o único indicativo sobre as manifestações esportivas se refere ao inciso 2 do artigo 217: "a destinação de recursos públicos para a promoção prioritária do desporto educacional e, em casos específicos, para a do desporto de alto rendimento".

Quando observamos que cabe ao município a oferta do ensino fundamental e que nele são obrigatórias as aulas de educação física, em que um dos conteúdos é o esporte, é possível afirmar que todos os municípios estão garantindo o fomento ao esporte e dando prioridade ao gasto no esporte educacional, aqueles praticados nos sistemas de ensino (BRASIL, 1998). Alguns condicionantes são necessários para que ocorra a prática do esporte na escola: a existência de espaço, de equipamentos esportivos, de materiais esportivos e de um profissional de educação física. Para o conjunto ou parte desses compromissos é necessário recurso financeiro.

Mesmo que apenas 38,2\% (34) da amostra tenha indicado que é dever do município fomentar a prática esportiva em suas leis orgânicas, $100 \%$ da amostra realiza gastos com o esporte educacional. Portanto, a norma municipal não reflete com precisão o que de fato acontece em termos da garantia do direito ao esporte. Nos termos mínimos colocados pela constituição (norma de eficácia não plena), todos os municípios do estado de Santa Catarina agem em conformidade com a norma superior.

\section{Análise das normas}

Os vinte municípios da amostra que indicaram competências para com a agenda esportiva em suas leis orgânicas apresentaram diferentes níveis de eficácia. As competências não plenas utilizaram os verbos 'promover', 'estimular' e 'incentivar' para indicar seu nível de compromisso. São verbos que não dão precisão à ação. Necessitam de regulamentação para indicar com precisão o significado que deve ser atribuído. 
Políticas de esporte, lei orgânica e financiamento nos municípios catarinenses Edmilson Santos dos Santos

Apenas oito municípios indicaram com precisão o nível de compromisso que os municípios devem ter com a agenda esportiva: $87,5 \%$ (7) indicaram a necessidade de o município realizar programas de apoio à prática esportiva e $25 \%$ (2) indicaram a necessidade de se construir parques e praças para a recreação.

Nas seções que tratam do esporte, 56,69\% (46) indicaram normas quanto à necessidade de investir em políticas de esporte. A maior parte desses, $86,96 \%$ (40), reproduziu aquilo que está previsto na constituição, dando prioridade ao esporte educacional.

Quanto ao financiamento, dois comportamentos foram observados. Em um deles, a eficácia garantida está na necessidade de se atribuir recurso à agenda, embora não seja especificado o percentual do compromisso - Salto Veloso: “O Município consignará dotação orçamentária para manutenção e apoio à Comissão Municipal de Esporte para a execução de suas atividades"; Ouro: "O município garantirá recurso destinado ao esporte amador, como forma de incentivo a competições desportivas e ao lazer"; Luzerna: "garantir a destinação de recursos para a promoção do desporto comunitário, de iniciação e de rendimento, nas zonas urbanas e rurais". Já o município de Rio do Oeste indicou o percentual do comprometimento: “O Município destinará um percentual que não será inferior a 1\% (um por cento) das despesas globais do orçamento anual" às políticas esportivas.

No que concerne aos recursos, considerando os dois comportamentos descritos acima, apenas 5,62\% (5) dos municípios indicaram na norma a garantia da necessidade de alocação de recursos às políticas de esporte, ainda que, na maioria dos casos, falte especificar o volume de recursos. Para esses, a não alocação não está no horizonte da discricionariedade.

Já 29,21\% (26) da amostra indicaram algum tipo de compromisso com a instalação de equipamentos esportivos. A maior parte desses municípios preferiu colocar normas de eficácia garantida nesse tema, exigindo criação/construção, instalação ou adequação dos locais existentes às práticas esportivas (96,15\%: 25). Apenas os 
Políticas de esporte, lei orgânica e financiamento nos municípios catarinenses Edmilson Santos dos Santos

municípios de Gaspar e de Águas Frias utilizaram termos menos precisos, como estimular a construção ou manutenção de áreas para recreação. Como podemos observar, em termos de equipamentos, há predominância de normas de eficácia garantida, exigindo um comportamento proativo dos governos municipais.

No âmbito dos programas, apenas três municípios apontaram normas específicas: Criciúma, Forquilhinha e Itapiranga. Os três reproduzem o mesmo texto: "Fica criado o programa desportivo e recreativo, com o qual o Município se obrigará a construir quadras esportivas polivalentes nas comunidades". No entanto, as leis orgânicas não especificam que tipo de programa ficou criado. Itapiranga escreveu que o município desenvolverá programas. Ou seja, os municípios estão condicionados pela norma, apesar da falta de especificação, a criar algum tipo de programa.

Diferentemente do que foi encontrado por Santos, Freire e Bastos (2017), não é possível afirmar que as normas são deficitárias. Apesar das limitações, elas buscam alcançar diferentes perspectivas de atenção ao esporte. Algumas delas especificando de forma precisa o tipo de comportamento que o poder executivo deve ter (normas de eficácia garantida); outras indicando outros tipos de compromissos que exigem regulamentação.

\section{Análise da adesão}

A adesão dos municípios catarinenses à agenda de gasto em políticas de esporte foi de $90,73 \%$. A adesão de $100 \%$ foi alcançada por 57,29\% (169) dos municípios. Ou seja, mais da metade deles implementam políticas esportivas sem que existam constrangimentos no âmbito da engenharia federalistas (distribuição de competências entre os entes federados). Não houve um único a não investir em políticas esportivas durante o período analisado. Apenas 3,73\% (11) investiram menos da metade do período. 
Políticas de esporte, lei orgânica e financiamento nos municípios catarinenses Edmilson Santos dos Santos

Os diferentes comportamentos alocativos são compatíveis com um modelo de gestão que garante autonomia, inclusive à inação, por parte dos municípios, quando se trata de financiamento das políticas de esporte. No entanto, os resultados não são desprezíveis quando comparamos políticas regulamentadas pela federação. A universalização da educação, em 2002 (97\%), se deu por conta dos incentivos da federação (FUNDEF2) para estimular a participação dos municípios na oferta do ensino básico (OLIVEIRA, 2007). Somente em 2007, mediante fortes incentivos da federação, 90\% dos municípios conseguiram garantir Equipes de Saúde da Família sob forte regulação federal (MARSIGLIA, 2012). Ou seja, a concertação federativa exige, para universalizar, forte aparato normativo federal, algo não alcançado pelas políticas esportivas. No entanto, seus índices de adesão à agenda são compatíveis com modelos que universalizaram via regramento federal, embora do ponto de vista financeiro possa haver problemas.

Como pode ser observado na Tabela 1, apenas a subamostra 'a' obteve adesão abaixo de $90 \%$ no período. A subamostra 'b' alcançou percentuais acima de $90 \%$ em todos os períodos e o meIhor resultado ano a ano. A maior diferença em termos de pontos percentuais (pp) é entre a subamostra 'a' e 'b'. Isso demonstra que os municípios que não apresentam normas de eficácia garantida apresentam mais dificuldades de garantir adesão à agenda de investimento em políticas esportivas.

Tabela 1. Adesão dos municípios à agenda de gasto em políticas esportivas.

\begin{tabular}{|l|c|c|c|c|c|}
\hline \multirow{2}{*}{ Municípios SC } & \multicolumn{5}{|c|}{ \% Adesão } \\
\cline { 2 - 6 } & Total & G1 & G2 & G3 & 100 \\
\hline População & 90,73 & 91,36 & 90,51 & 90,34 & 57,29 \\
\hline Amostra & 90,26 & 92,42 & 89,33 & 89,04 & 57,3 \\
\hline subamostra "a" & 88,39 & 90,63 & 86,61 & 87,95 & 53,57 \\
\hline subamostra "b" & 93,43 & 95,46 & 93,94 & 90,91 & 63,64 \\
\hline
\end{tabular}

Fonte: Dados da pesquisa.

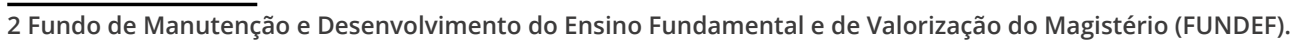


Políticas de esporte, lei orgânica e financiamento nos municípios catarinenses Edmilson Santos dos Santos

Considerando o percentual de municípios que não dispõem de normas de eficácia garantida em suas leis orgânicas, mas garantiram investimentos durante todo o período, essa evidência inibe afirmação precisa de que as normas de eficácia definem o tipo de comportamento frente às demandas do setor esportivo. No entanto, o fato dos municípios que não apresentaram normas de eficácia garantida exibirem os piores resultados em termo de adesão é um indicativo de que esses municípios reúnem uma série de características (comuns ou não entre si) que os fragilizam diante das demandas do setor esportivo e ajudam a pressionar para baixo a adesão.

Somente um município que garantiu norma de eficácia garantida na seção que trata das competências não obteve 100\% de adesão. O município de Urupema garantiu adesão em 10 anos (83,33\%). No entanto, como pode ser observado na Tabela 1, essa não é uma prerrogativa associada à existência ou não de normas de eficácia plena na seção que trata das competências dos municípios.

A adesão à agenda não é fator exclusivo, apesar de importante, à análise da participação dos municípios no financiamento das políticas esportivas. O volume de recurso, ao lado da adesão, responde de forma mais adequada à participação dos municípios no financiamento das políticas públicas esportivas. Dois aspectos tornam-se importantes de serem analisados. Um deles é a evolução do gasto considerando a variação no longo prazo, de 2005 a 2016. $\mathrm{O}$ outro diz respeito à evolução do resultado entre as gestões.

Como pode ser observado na Tabela 2, o volume de investimento no período apontou crescimento. Considerando os recursos investidos em 2005 e, ao final, 2016, o crescimento foi de 21,3\%. Portanto, a agenda de gasto em políticas públicas esportivas obteve crescimento no volume de gasto no período, demonstrando valorização da agenda (RIBEIRO, 2006). O resultado negativo da amostra é fortemente pressionado pelo grupo de municípios que não apresentam normas de eficácia plena e mostraram a maior retração (-27,38\%). E o grupo de municípios que apresentam as 
Políticas de esporte, lei orgânica e financiamento nos municípios catarinenses Edmilson Santos dos Santos

normas de eficácia garantida (subamostra 'b') alcançou a maior elevação de recurso no período, 46,23\%.

Tabela 2. Variação da adesão e do volume de recurso em políticas de esporte (\%).

\begin{tabular}{|l|c|c|c|c|c|c|c|}
\hline \multirow{2}{*}{ Municípios SC } & $\mathrm{n}$ & \multicolumn{2}{c|}{$2005 / 2016$} & \multicolumn{2}{c|}{ G1/G2 } & \multicolumn{2}{c|}{ G2/G3 } \\
\cline { 3 - 8 } & & Adesão & Recursos & Adesão & Recursos & Adesão & Recursos \\
\hline População & 295 & 4,81 & 21,3 & $-0,7$ & 21,72 & 1,05 & $-1,63$ \\
\hline Amostra & 89 & 7,69 & $-3,99$ & $-4,55$ & 15,01 & 3,57 & $-7,46$ \\
\hline Subamostra "a" & 56 & 12,77 & $-27,38$ & $-5,55$ & 5,68 & 3,85 & $-26,43$ \\
\hline Subamostra "b" & 33 & 0 & 46,23 & $-3,03$ & 34,84 & 3,13 & 23,65 \\
\hline
\end{tabular}

Fonte: Dados da pesquisa.

Considerando que a norma pode ser o resultado de um ambiente político cultural de maior valorização da agenda esportiva, tanto a norma como a evolução do recurso podem estar respondendo a esse ambiente. Apesar de, no último período (G2/G3), o crescimento ter sido menor que no anterior (G1/G2), o resultado demonstra consistência na evolução dos recursos, mesmo quando consideramos a queda na adesão no primeiro período (-3,03\%).

Os municípios pertencentes à subamostra 'a' são aqueles que apresentaram os piores resultados. Entre 2005 e 2016, acumularam uma retração do volume de recursos da ordem de 27,38\%, apesar do crescimento na adesão de 12,77\%. A ampliação se deu combinada com redução do financiamento. Tanto na variação da adesão como na variação dos recursos, os municípios que compõem a subamostra 'a' são os mais frágeis na garantia de recursos à implementação de políticas públicas de esporte.

A existência de normas de eficácia garantida no âmbito das leis orgânicas, para a realidade aqui analisada, não é um bom preditor do comportamento dos municípios quanto à agenda de gasto em políticas esportivas. Primeiramente porque, mesmo não tendo esses dispositivos normativos, mais da metade dos municípios da amostra (e da subamostra 'a') garantiram mais de $50 \%$ de adesão à agenda durante todo o período. Além disso, não impediu que houvesse a inação em termos de investimentos em políticas públicas de esporte em algum ano. 
Políticas de esporte, lei orgânica e financiamento nos municípios catarinenses Edmilson Santos dos Santos

Os resultados apresentados são compatíveis com a oferta descentralizada de políticas públicas pelo ente municipal. A inexistência de percentuais de gastos ou de obrigatoriedade de investimentos permite que a cada ano os municípios tenham diferentes comportamentos alocativos, pois as capacidades técnicas podem se diferenciar (ABRUCIO; FRANZE, 2007) ou porque eles experimentam de forma plena a autonomia (ARRECTHE, 1999).

Mesmo as normas de eficácia garantida não sendo decisivas para garantir distinção no nível de adesão ou de gasto, é perceptível que eles apresentam comportamento muito distinto da população, da amostra e da subamostra 'a'. Ou seja, eles reúnem certas características que ajudaram a produzir as normas de eficácia plena, garantir níveis elevados de adesão e apresentam variação positiva em termos de alocação dos recursos financeiros no longo prazo e por gestão, como ficou evidente na Tabela 2.

\section{Conclusão}

Os estudos que analisam o comportamento de gasto dos municípios apontam com bastante precisão que é esse nível de governo que mais investe em políticas públicas esportivas. Portanto, é um player estratégico para conhecermos o que o Estado brasileiro produz em termos de política esportiva.

Dessa forma, lançar luz sobre possíveis relações entre a variável normativa e a variável financeira pode nos ajudar a melhor compreender a produção dessa realidade, objetivo central deste estudo. Em linhas gerais, o que podemos observar é uma realidade muito intrigante quando associamos as normas e os investimentos. Normas de eficácia garantida, por si só, não asseguram efetividade na adesão, e as normas de eficácia não garantida não provocam, por si só, a inação. No entanto, algumas evidências nos ajudam a pensar nessa complexidade:

(a) os legisladores municipais preferiram não imputar responsabilidades objetivas no âmbito das competências municipais à agenda esportiva; 
Políticas de esporte, lei orgânica e financiamento nos municípios catarinenses Edmilson Santos dos Santos

(b) a agenda esportiva assume diferentes significados nas leis orgânicas que vão da indicação de algum tipo de obrigatoriedade (ação) até prescrições pouco precisas, como 'fomentar a prática esportiva';

(c) a adesão ao gasto no esporte é muito apreciada e desejada pelos decisores locais, mesmo diante da inexistência de constrangimentos no âmbito da federação e das leis orgânicas;

(d) a valorização da agenda pode ser observada na variação do gasto da população e da subamostra 'b';

(e) a existência de normas de eficácia garantida atua fortemente na direção de elevar os níveis de adesão e da variação positiva dos investimentos;

Os resultados aqui apresentados apontam desafios importantes para uma melhor compreensão do papel do Estado na implementação das políticas de esporte, principalmente quando se trata de análises das instituições (formais e informais). Assim como outras realidades já investigadas do ponto de vista dos gastos na FDL, a realidade dos municípios de Santa Catarina é mais um exemplo positivo a ser observado. Além disso, os níveis de adesão, os investimentos e as competências normativas exigem um conhecimento mais preciso dessa realidade (e das Unidades da Federação) antes de avançarmos em direção à produção de normas para o setor esportivo no âmbito da federação.

\title{
Bibliografia
}

\begin{abstract}
ABRUCIO, F. L.; FRANZESE, C. Federalismo e políticas públicas: o impacto das relações intergovernamentais no Brasil In: Maria Fátima Infante Araújo; Lígia Beira. (Org.). Tópicos de Economia Paulista para Gestores Públicos. 1 ed. Edições FUNDAP: São Paulo, 2007, v. 1, p. 13-31.

ARRETCHE, M. Federalismo e igualdade territorial: uma contradição em termos? Dados, Rio de Janeiro, v. 53, n. 3, p. 587-620, 2010.
\end{abstract}


Políticas de esporte, lei orgânica e financiamento nos municípios catarinenses Edmilson Santos dos Santos

ARRETCHE, M. Políticas sociais no Brasil: descentralização em um Estado federativo. Revista Brasileira de Ciências Sociais, São Paulo, v. 14, n. 40, p. 111-141, jun. 1999.

AVILA, M.; BAHIA, C.; ROSA, C. Gestão esportiva e de lazer uma análise de sites oficiais de 59 municípios baianos. Motrivivência, Florianópolis, v. 31, n. 58, p. 1-18, 2019.

BRASIL. Constituição da República Federativa do Brasil (1988). Diário Oficial [da] República Federativa do Brasil, Brasília, DF, 05 out. 1988. Disponível em: http://www.planalto.gov.br/ccivil_03/ Constituicao/Constituicao.htm. Acesso em: 15 out. 2019.

BRASIL. Lei n. 9.615, de 24 de março de 1998. Institui normas gerais sobre desporto e dá outras providências. Diário Oficial [da] República Federativa do Brasil, Brasília,

DF, 25 mar. 1998. Disponível em: http://www.planalto.gov.br/ccivil_03/leis/L9615consol.htm. Acesso em: 07 ago. 2019.

BRASIL. Ministério do Planejamento, Orçamento e Gestão. Portaria n. ${ }^{\circ}$ 42, de 14 de abril de 1999. Diário Oficial [da] República Federativa do Brasil, Brasília, DF, 14 abr. 1999. Disponível em: ftp://ftp.fnde.gov.br/web/siope/leis/P42_ MPOG_14-041999.pdf. Acesso em: 20 out. 2019.

CRICIÚMA. Lei Orgânica Municipal de Criciúma de 05 de julho de 1990, Salto Veloso, SC, jul. 1990. Disponível em: https://leismunicipais.com.br/lei-organica-criciuma-sc. Acesso em: 14 out. 2018. FORQUILHINHA. Lei Orgânica Municipal de Forquilhinha de 15 de novembro de 1990, Salto Veloso, SC, nov. 1990. Disponível em: https://www.camaraforquilhinha.sc.gov.br/documento/lei-organica-de-forquilhinha-1380. Acesso em: 14 out. 2018.

GRASSO, R. P.; ISAYAMA, H. F. Financiamento e políticas públicas de esporte e lazer: uma análise da gestão no município de Santarém/PA (2005-2012). Revista Brasileira de Ciência e Movimento, v. 25, n. 1, p. 151-167, 2017.

HALL, Peter A.; TAYLOR, Rosemary C. R. As três versões do neo-institucioalismo. Lua Nova, n. 58, p. 193-222, 2003. 
Políticas de esporte, lei orgânica e financiamento nos municípios catarinenses

ITAPIRANGA. Lei Orgânica Municipal de Itapiranga de 11 de novembro de 1990, Salto Veloso, SC, abr. 2013. Disponível em: https://www.camaraforquilhinha.sc.gov.br/documento/lei-organica-de-forquilhinha-1380. Acesso em: 14 out. 2018.

LENZA, P. Direito Constitucional Esquematizado. São Paulo: Saraiva, 2008.

LUZERNA. Lei Orgânica Municipal de Luzerna de 27 de novembro de 1997, Salto Veloso, SC, nov. 1997. Disponível em: https://leismunicipais.com.br/lei-organica-luzerna-sc. Acesso em: 14 out. 2018.

MARCH, J.; OLSEN, J.P. Neo-Insticuionalismo: fatores organizacionais na vida política. Revista Sociologia e Política, Curitiba, v. 16, n. 31, p. 121-142, nov. 2008.

MARSIGLIA, R. M. G. Universalização do acesso ao Sistema Único de Saúde no Brasil: desafios para a Atenção Primária à Saúde/ Universalization of the access to the Unified Health System in Brazil: challenges for the Primary Health Care. Cadernos Brasileiros de Terapia Ocupacional, São Carlos, v. 20, n. 3, p. 317-325, 2012.

MENDES, A.D. A política da política de esporte: uma análise da Frente Parlamentar do Esporte e da Comissão do Esporte da Câmara dos Deputados na 54a Legislatura. 2017. 245 f. Tese (Doutorado em Políticas Públicas), Setor de Ciências Sociais Aplicadas, Universidade Federal do Paraná, Curitiba, 2017. OLIVEIRA, R. P. Da universalização do ensino fundamental ao desafio da qualidade: uma análise histórica. Educação \& Sociedade, Campinas, v. 28, n. 100, 661-690, 2007.

OURO. Lei Orgânica Municipal de Ouro de 02 de abril de 1990, Salto Veloso, SC, jul. 2013. Disponível em: https://static.fecam.net. br/uploads/286/arquivos/214268_Lei_Organica_do_Municipio_de_ Ouro.pdf . Acesso em: 13 out. 2018.

RIBEIRO, L. M. Partidos políticos e gastos sociais nos municípios brasileiros. In: $5^{\circ}$ ENCONTRO DA ABPC, 2006, Anais... Belo Horizonte, 2006. 
Políticas de esporte, lei orgânica e financiamento nos municípios catarinenses

RIO DAS OSTRAS. Lei Orgânica Municipal de Rio das Ostras DE 09 DE JUNHO DE 1994, Rio das Ostras, RJ, jun 1994. Disponível em: http://www.riodasostras.rj.gov.br/download/leis-e-codigos/leis/ lei-organica-emenda-01-a-35.pdf. Acesso em: 13 out. 2017. RIO DO OESTE. Lei Orgânica Municipal de Rio do Oeste de 13 de julho de 1990, Salto Veloso, SC, jul. 1990. Disponível em: http:// www.riodooeste.com.br/img/imagens/legis/LOM.pdf . Acesso em: 14 out. 2018.

SALTO VELOSO. Lei Orgânica Municipal de Salto Veloso de 29 de março de 1990, Salto Veloso, SC, abr. 2001. Disponível em: https://static.fecam.net.br/uploads/823/arquivos/586434_Lei_ Organica_do_Municipio_de_Salto_Veloso.pdf . Acesso em: 13 out. 2018.

SANTOS, E. S. Gasto na Função Desporto e Lazer pelos municípios do estado do Maranhão. Revista Intercontinental de Gestão Desportiva, v. 8, p. 138-150, 2018.

SANTOS, E. S.; CARVALHO, M. J.; FROES, G. S. Investimento na Função Desporto e Lazer (FDL) por parte dos municípios dos estados do Acre, Amapá, Rondônia e Roraima. Revista Intercontinental de Gestão Desportiva, v. 9, p. 1-16, 2019. SANTOS, E. S.; MILANI, F. G.; REVERDITO, R. S.; STAREPRAVO, F. A. O financiamento do esporte e do lazer pelos municípios do estado do Mato Grosso de 2005 a 2008. Revista Licere, Belo Horizonte, v. 22, p. 49-69, 2019.

SANTOS, E. S.; SANTOS, A. G. Participação dos municípios do estado do Espírito Santo nos gastos da Função Desporto e Lazer. Revista Conexões, Campinas, v. 16, 2018.

SANTOS, E. S.; STAREPRAVO, F. A. Political-Administrative Structure of Municipal Governments in Piauí and Investment in Sport and Leisure. Revista Licere, Belo Horizonte, v. 21, p. 166183, 2018.

SANTOS, E. S.; STAREPRAVO, F. A.; CANAN, F. Evolução das despesas da função desporto e lazer (FDL) dos municípios do estado do 
Políticas de esporte, lei orgânica e financiamento nos municípios catarinenses

Piauí de 2003 a 2011. Motrivivência, Florianópolis, v. 30, p. 20-33, 2018.

SANTOS, E.S.; CANAN, F.; STAREPRAVO, F.A. Investimentos na Função Desporto e Lazer por parte dos municípios da Bahia de 2002 a 2011. Journal of Physical Education, Maringá, v. 29, p. 2-10, 2018.

SANTOS, E.S.; MENEZES, V.G.; LIMA, E.W.G. Investimento na função desporto e lazer (FDL) dos municípios de Pernambuco no ano de 2013 por níveis de dependência do Fundo de Participação dos Municípios (FPM). Revista Brasileira de Ciências do Esporte, Brasília, v. 41, p. 34-40, 2019.

SANTOS, E.S.; STAREPRAVO, F.A.; MENEZES, V.G.; MELO, E.H.R. Municípios e propostas vulneráveis: uma análise do edital 2013 do Programa Esporte e Lazer da Cidade (PELC). Pensar a Prática, Goiânia, v. 22, p. 1-11, 2019.

SANTOS, E.S; HIRATA, E. Investimento Na Função Desporto E Lazer Por Níveis de Índice de Desenvolvimento Humano.

Caderno de Educação Física, Marechal Cândido Rondon, v. 15, p. 49-55, 2017.

SANTOS, M. A. G.; FREIRE, E. D. S.; BASTOS, F. D. C. O esporte nas leis orgânicas municipais e as políticas de gestão. Revista Licere, Belo Horizonte, v. 20, n. 4, 249-288, 2017.

SILVA, J.A. Aplicabilidade Das Normas Constitucionais. $8^{\text {a }}$ Ed. São Paulo: Malheiros, 2012.

SOUZA, N. B.S.; LIMA, S. A.; MENEZES, M. L.; RAIMUNDO, L.A.; MENEGALDO, P. H. I. Análise do orçamento destinado a política esportiva no município de Barra do Rocha/BA. Anais... III Simpósio Orçamento Público e Políticas Sociais: o controle social como instrumento político na gestão do orçamento público. Maringá, out. 2017 THÉRET, B. As instituições entre as estruturas e as ações. Lua Nova, São Paulo, n. 58, p. 226-254, 2003. 
Políticas de esporte, lei orgânica e financiamento nos municípios catarinenses Edmilson Santos dos Santos

WERLE, V.; VAZ, A. Sobre a constituição e desenvolvimento da legislação esportiva de Florianópolis (1986 - 2015). Revista Licere, Belo Horizonte, v. 22, n. 1, p. 331-358, mar. 2019.

\section{Publisher}

Universidade Federal de Goiás. Faculdade de Educação Física e Dança. Publicação no Portal de Periódicos UFG. As ideias expressadas neste artigo são de responsabilidade de seus autores, não representando, necessariamente, a opinião dos editores ou da universidade. 